\title{
A three-dimensional hysteretic soil-water retention curve
}

\author{
A. TSIAMPOUSI*, L. ZDRAVKOVIĆ and D. M. POTTS
}

\begin{abstract}
One of the most important features in unsaturated soil mechanics is the soil-water retention curve and its coupling to the mechanical component of soil behaviour. It has long been recognised that the retention curve exhibits significant hysteresis, and that it is affected by the specific volume. Several attempts have been made in the past to model this behaviour. A novel approach is proposed herein, which accounts for both the hydraulic hysteresis and the specific volume dependence of the retention relationship in a three-dimensional formulation. The primary and the scanning paths are simple geometric curves, which have a common tangent at the point of intersection, ensuring a smooth transition from scanning to primary paths. A small number of parameters are required to define the primary paths, and no fitting parameters are necessary for generation of the scanning paths. As knowledge of the specific volume and its variation is required, the retention model needs to be employed in conjunction with a constitutive model capable of reproducing the complex behaviour of unsaturated soils. To guarantee consistency with the retention model, the degree of saturation needs to be incorporated in the specific volume-suction relationship adopted within the constitutive model. To accommodate such a feature when absent, a new expression for the soil compressibility with suction as a function of the degree of saturation is proposed. Simulations of laboratory experiments on unsaturated soils, involving cyclic changes of applied suction, demonstrate the effectiveness of the proposed modelling approach.
\end{abstract}

KEYWORDS: constitutive relations; partial saturation; suction

\section{INTRODUCTION}

For unsaturated soils the degree of saturation, $S_{\mathrm{r}}$, generally reduces with increasing suction, $s$, following the soil-water retention curve (SWRC). Although the SWRC may be plotted in terms of the volumetric water content, in constitutive modelling it is commonly defined in terms of the degree of saturation, $S_{\mathrm{r}}$, and this definition has been employed throughout the current paper. The SWRC is not unique; it may exhibit a hysteretic behaviour upon cyclic changes of suction, and is affected by the variation of the void ratio. When a reconstituted sample is dried from initially saturated to residual conditions and is subsequently wetted to full saturation it follows the primary paths. These bound an infinite number of scanning paths, which are followed on drying or wetting from an initial retention point lying in between the primary paths, or on drying (wetting) from an initial retention point lying on a primary wetting (drying) path. Furthermore, changing the dimension of the voids and of passageways between them affects the position of the retention curve (Vanapalli et al., 1999; Sugii et al., 2002; Gallipoli et al., 2003b).

Several authors have attempted to include the hydraulic hysteresis into numerical modelling of unsaturated soils (Wheeler, 1996; Vaunat et al., 2000; Wheeler et al., 2003; Li, 2005; Sun et al., 2007; Nuth \& Laloui, 2008; Lloret et al., 2009; Pedroso \& Williams, 2010). In the models by $\mathrm{Li}$ (2005) and Pedroso \& Williams (2010), which adopt a realistic shape for the primary and the scanning paths, the latter approach the former asymptotically. An alternative and novel idea is proposed here, where the primary and the scanning paths are simple geometric curves which have a

Manuscript received 23 June 2011; revised manuscript accepted 13 June 2012. Published online ahead of print 1 October 2012.

Discussion on this paper closes on 1 July 2013, for further details see p. ii.

* Department of Civil and Environmental Engineering, Imperial College London, UK. common tangent at the point of intersection. The effect of specific volume, $v$, is also accounted for, and the model is defined in $s-S_{\mathrm{r}}-v$ space. Nonetheless, the formulation and implementation of the model are handled in the two-dimensional space $s^{*}-S_{\mathrm{r}}$, where $s^{*}$ is the combined suction, which is a function of $v$, as later explained. Despite its geometric simplicity, the model has demonstrated effectiveness in the representation of laboratory data.

The SWRC model needs to be combined with a constitutive model capable of simulating the complex mechanical behaviour of unsaturated soils, so that the variation of $v$ during a numerical analysis is available. The SWRC model may be combined with simple elasto-plastic constitutive models formulated in terms of Bishop's effective stress or net stress and suction (e.g. Alonso et al., 1990; Toll, 1990; Wheeler \& Sivakumar, 1995; Cui \& Delage, 1996; Georgiadis et al., 2005). In the case of models formulated in terms of net stress, $S_{\mathrm{r}}$ is commonly included in specific features of the model, such as the apparent cohesion, in order to account for the effect of the SWRC on these features. More complex constitutive models, where sophisticated stress variables are employed, or which incorporate a SWRC within their formulation (e.g. Wheeler et al., 2003; Gallipoli et al., 2003a; Sheng et al., 2008), may not be suitable for use with the SWRC model proposed. A classification of constitutive models according to the stress variables adopted is given by Gens (2010), and an overview of recent advances in constitutive modelling of unsaturated soils is given by D'Onza et al. (2011).

In the present case, the SWRC model was used in conjunction with the Georgiadis et al. (2005) constitutive model, which displays some similarities to the Barcelona Basic Model (BBM) of Alonso et al. (1990). In the Georgiadis et al. (2005) constitutive model, the increase of apparent cohesion with suction is a function of the degree of saturation, providing a link to the SWRC. However, the constitutive model assumes a unique relationship between the specific volume and the suction under constant applied 
stress, as in the BBM. This feature is in contradiction with the three-dimensional relationship between the specific volume, the suction and the degree of saturation of the SWRC model. Consequently, a new expression, linking the soil compressibility with suction to the degree of saturation, is proposed and implemented in the Georgiadis et al. (2005) constitutive model.

The formulation of the above-mentioned model enhancements and their implementation in the Imperial College finite-element program (ICFEP) (Potts \& Zdravkovic, 1999) are subsequently presented, followed by their calibration with laboratory data.

\section{MODELLING OF THE SOIL-WATER RETENTION CURVE \\ Formulation}

The three-dimensional hysteretic SWRC model developed was aimed at satisfying two fundamental requirements: (a) the need for a realistic shape for both the primary and the scanning paths; and (b) the necessity for a smooth transition from scanning to primary paths.

The first requirement arises from the fact that the slope of the retention curve is essential in a coupled analysis, as it affects the flow of water. More specifically, the flow generated by changes in water content, and therefore in the degree of saturation, is dependent on the gradient of the SWRC, which controls the water storage within the soil (Wong et al., 1998; Smith, 2003). Therefore realistic shapes for the primary and the scanning paths are of importance.

The second requirement, for a smooth transition from one type of path to the other, relates to numerical singularities. The robustness of the model is believed to be improved when abrupt changes of the gradient of the retention curve are avoided.

The model is formulated in terms of degree of saturation $S_{\mathrm{r}}$, specific volume $v$ and equivalent suction $s_{\mathrm{eq}}$, where $s_{\mathrm{eq}}=s-s_{\mathrm{air}}, s$ being the matric suction (the term 'suction' is used throughout for simplicity) and $s_{\text {air }}$ being the air-entry value of suction. For suction levels lower than the air-entry value the model is not employed, as full saturation is assumed and $S_{\mathrm{r}}=1 \cdot 0$. This assumption, made in the interests of simplicity, neglects the air-occlusion value of suction, which is typically smaller than $s_{\text {air }}$ and is in contradiction with experimental evidence (e.g. Romero et al., 1999; Tarantino, 2009; Airo Farulla et al., 2010). However, as the same assumption holds for the relevant constitutive model within ICFEP (Georgiadis et al., 2005), which was employed in conjunction with the proposed developments, consistency is guaranteed.

Being formulated in space, rather than in a plane, the model adopts the notion of drying and wetting surfaces, rather than drying and wetting curves. The concept of a surface in $s-S_{\mathrm{r}}-v$ space has previously been employed by Gallipoli et al. (2003b) and Salager et al. (2010), but not in a hysteretic form. The primary drying and wetting surfaces are shown schematically in Fig. 1, and are assumed to bound an infinite number of scanning surfaces, which, for reasons of clarity, are not presented in the figure. The primary drying surface (lightly coloured in the figure) lies above the primary wetting one (dark coloured) for the whole range of specific volume values.

Also shown in Fig. 1 are hypothetical retention curves followed upon primary drying under constant specific volume (black lines), referred to herein as primary drying isovolumetric SWRCs. Similar iso-volumetric SWRCs correspond to primary wetting, and lie on the primary wetting surface, but are not shown in the figure for simplicity. It is interesting to note that the shape of the iso-volumetric

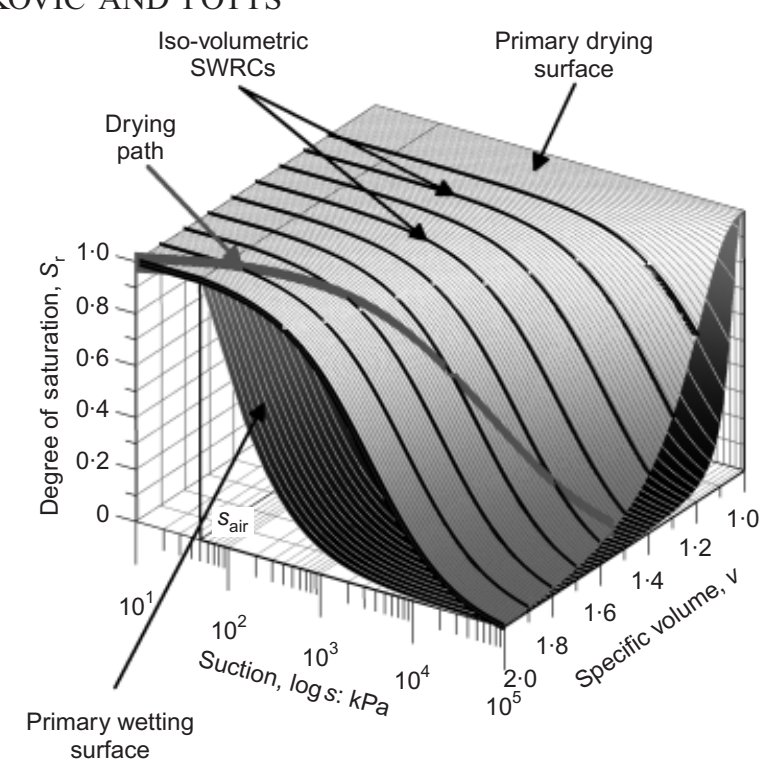

Fig. 1. Three-dimensional hysteretic soil-water retention surface in $s-S_{\mathrm{r}}-v$ space

SWRCs resembles the S-shape that is typically obtained from laboratory measurements, and which is predicted by the Van Genuchten (1980) expression. By decreasing the specific volume, larger degrees of saturation, $S_{\mathrm{r}}$, correspond to the same suction level, while for the theoretical case where $v \rightarrow 1.0$ fully saturated conditions are sustained throughout the suction range. Projecting the primary drying isovolumetric curves onto the $s-S_{\text {r }}$ plane, the image illustrated in Fig. 2 is obtained. Evidently, the position of the curves is moved upwards or downwards depending on whether the specific volume is decreasing or increasing respectively. The distance between the projected iso-volumetric SWRCs depends on the model parameter $\psi$ (see below).

An unsaturated soil, such as the bentonite-kaolin mixture tested by Sharma (1998), may exhibit changes of volume during mechanical loading (i.e. changes in applied stress) or hydraulic loading (i.e. changes in applied suction). Gradual changes of the specific volume impose a continuous shift of the retention relationship from one iso-volumetric curve to the next, and in the example of Fig. 1 the retention point, defined in $s-S_{\mathrm{r}}-v$ space, moves on the primary drying surface. Similarly, on drying or wetting from an initial point lying in between the primary surfaces, the retention point travels on a three-dimensional scanning surface that rejoins the primary drying or primary wetting surface.

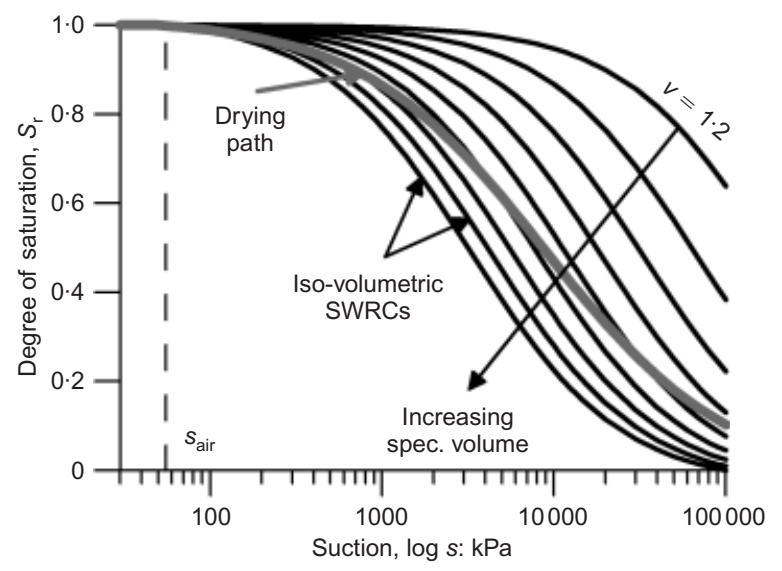

Fig. 2. Projection in $s-S_{\mathrm{r}}$ plane of three-dimensional iso-volumetric SWRCs and of primary drying curve 
The above three-dimensional surfaces may be reduced to a two-dimensional hysteretic SWRC, illustrated schematically in Fig. 3, when plotted in the $s^{*}-S_{\mathrm{r}}$ plane, where $s^{*}=(v-1)^{\psi} s_{\text {eq }}$ is the combined suction. The parameter $\psi$, initially introduced by Gallipoli et al. (2003b), controls the effect of specific volume on the retention behaviour and the position of the iso-volumetric curves. The distance between them increases for increasing values of $\psi$. If $\psi=0.0$ there is no effect on the simulated behaviour. Note that when $v=2 \cdot 0$, the parameter $\psi$ has no effect on the behaviour, as $s^{*}=s_{\mathrm{eq}}$.

Clearly, the combined suction is a function of the currently applied equivalent suction and of the specific volume resulting from the coupled effect of the mechanical and the hydraulic loading. $s_{\mathrm{A}}^{*}$ is therefore the combined suction at a retention point $\mathrm{A}$ that is fully defined by three coordinates: the suction, $s$; the specific volume, $v$; and the degree of saturation, $S_{\mathrm{r}}$. Formulation of the SWRC model in terms of $s^{*}$ implies that both the primary and the scanning paths are specific volume dependent. The data of Tarantino (2009), who used the notion of normalised suction, defined in a similar way to the combined suction, support this hypothesis. The formulation of the primary and scanning curves is presented in terms of degree of saturation $S_{\mathrm{r}}$ and combined suction, $s^{*}$. A similar formulation may be applied in order to obtain a hysteretic SWRC model in the $s_{\mathrm{eq}}-S_{\mathrm{r}}$ or $s-S_{\mathrm{r}}$ planes - that is, ignoring the effect of specific volume on the retention behaviour, if the combined suction, $s^{*}$, is substituted by the equivalent suction, $s_{\text {eq }}$, as presented by Tsiampousi et al. (2010) and Tsiampousi (2011), or equally by the matric suction, $s$.

Primary drying and wetting paths. With reference to Fig. 3, desaturation during drying and full saturation during wetting are assumed to occur at the air-entry value, $s_{\text {air }}$, for which $s^{*}=0 \cdot 0$ : that is, the air-entry and air-occlusion values of suction are assumed to be equal, as already explained. In this way, the primary paths have a common point $\left(s^{*}, S_{\mathrm{r}}\right)=(0 \cdot 0$, $1 \cdot 0)$. Furthermore, in order to ensure smooth transition from primary drying to primary wetting, the closing point of the primary loop is also common, and it is assumed to occur at $0 \cdot 0$ degree of saturation (the last assumption was made so that the number of model parameters is minimised). The corresponding value of combined suction, $s_{0}^{*}$, is a model parameter. The following S-shape curve is adopted for the

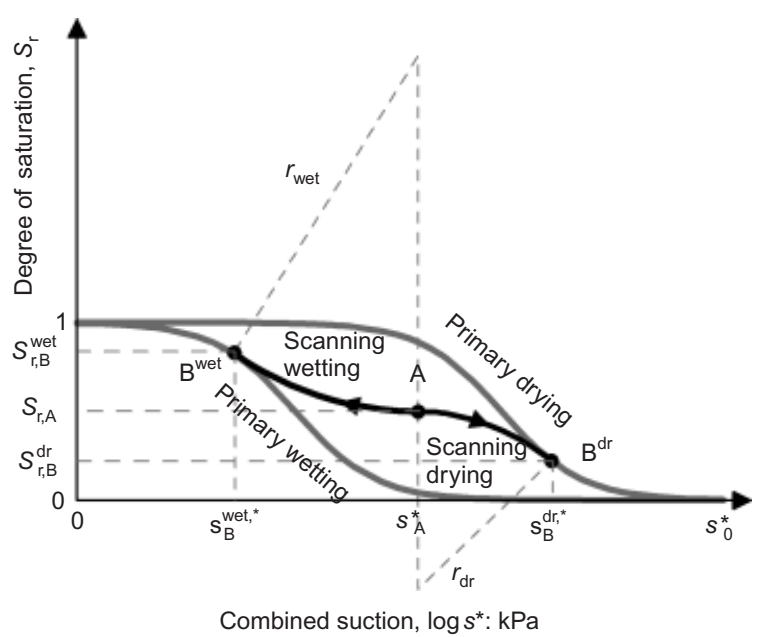

Fig. 3. Projection in $s^{*}-S_{\mathrm{r}}$ plane of three-dimensional soil-water retention surface primary drying $\left(S_{\mathrm{r}, \mathrm{pr}}^{\mathrm{dr}}\right)$ and the primary wetting $\left(S_{\mathrm{r}, \mathrm{pr}}^{\mathrm{wet}}\right)$ curves in the $s^{*}-S_{\mathrm{r}}$ plane.

$$
S_{\mathrm{r}, \mathrm{pr}}^{\text {dr.wet }}=\frac{1-\left(1 / s_{0}^{*}\right) s^{*}}{1+\alpha_{\mathrm{d}, \mathrm{w}} s^{*}}
$$

where $\alpha$ is a fitting parameter, carrying the index $\mathrm{d}$ for drying and $w$ for wetting. For the wetting path to lie beneath the drying path $\alpha_{\mathrm{w}}$ has to be larger than $\alpha_{\mathrm{d}}$, while if they are equal a non-hysteretic curve is generated.

The gradient of the primary paths for the current value of equivalent suction is

$$
\frac{\partial S_{\mathrm{r}, \mathrm{pr}}^{\mathrm{dr}, \mathrm{wet}}}{\partial s^{*}}=-\frac{\left(1 / s_{0}^{*}\right)+\alpha_{\mathrm{d}, \mathrm{w}}}{\left(1+\alpha_{\mathrm{d}, \mathrm{w}} s^{*}\right)^{2}}
$$

Scanning drying and wetting paths. On drying from an initial retention point $\mathrm{A}$, defined in the $s^{*}-S_{\mathrm{r}}$ plane by its coordinates $\left(s_{\mathrm{A}}^{*}, S_{\mathrm{r}, \mathrm{A}}\right)$ and positioned in between the two primary curves, the soil is assumed to follow the scanning path $\mathrm{AB}^{\mathrm{dr}}$ shown in Fig. 3. This scanning path is assumed to be the arc of a circle in the $\log s^{*}-S_{\mathrm{r}}$ plane, centred on the vertical line passing through point $\mathrm{A}$ so that the combined suction corresponding to the centre of the circle is equal to the combined suction at point $\mathrm{A}, s_{\mathrm{A}}^{*}$. The circle and the primary drying curve have a common tangent at point $\mathrm{B}^{\mathrm{dr}}$ $\left(s_{\mathrm{B}}^{\mathrm{dr}},{ }^{*}, S_{\mathrm{r}, \mathrm{B}}^{\mathrm{dr}}\right)$, also shown in Fig. 3. In this way, the slope of the scanning path is always zero at point $\mathrm{A}$, and a smooth transition from the scanning to the primary drying path is provided at point $\mathrm{B}^{\mathrm{dr}}$. The radius of the circle, $r_{\mathrm{dr}}$, and the combined suction at point $\mathrm{B}^{\mathrm{dr}}, s_{\mathrm{B}}^{\mathrm{dr}}$,* , need to be identified.

The expression for the scanning drying path is

$$
S_{\mathrm{r}, \mathrm{scan}}^{\mathrm{dr}}=S_{\mathrm{r}, \mathrm{A}}-r_{\mathrm{dr}}+\left[r_{\mathrm{dr}}^{2}+\left(\log s^{*}-\log s_{\mathrm{A}}^{*}\right)^{2}\right]^{1 / 2}
$$

The slope of the scanning drying path for the current value of combined suction is

$$
\frac{\partial S_{\mathrm{r}, \mathrm{scan}}^{\mathrm{dr}}}{\partial s^{*}}=-\frac{\log s^{*}-\log s_{\mathrm{A}}^{*}}{s^{*} \ln 10}\left[r_{\mathrm{dr}}^{2}-\left(\log s^{*}-\log s_{\mathrm{A}}^{*}\right)^{2}\right]^{-1 / 2}
$$

As noted above, to define the scanning drying path, the radius $r_{\mathrm{dr}}$ is required. As $\mathrm{B}^{\mathrm{dr}}$ is a common point for the two curves given by equations (1) and (3), then

$$
\frac{1-\left(1 / s_{0}^{*}\right) s_{\mathrm{B}}^{\mathrm{dr}, *}}{1+\alpha_{\mathrm{d}} s_{\mathrm{B}}^{\mathrm{dr}, *}}=S_{\mathrm{r}, \mathrm{A}}-r_{\mathrm{dr}}+\left[r_{\mathrm{dr}}^{2}-\left(\log s_{\mathrm{B}}^{\mathrm{dr}, *}-\log s_{\mathrm{A}}^{*}\right)^{2}\right]^{1 / 2}
$$

Furthermore, the two curves share a common tangent at point $\mathrm{B}^{\mathrm{dr}}$

$$
\begin{aligned}
-\frac{\left(1 / s_{0}^{*}\right)+\alpha_{\mathrm{d}}}{\left(1+\alpha_{\mathrm{d}} s_{\mathrm{B}}^{\mathrm{dr}, *}\right)^{2}}= & -\frac{\log s_{\mathrm{B}}^{\mathrm{dr}, *}-\log s_{\mathrm{A}}^{*}}{s_{\mathrm{B}}^{\mathrm{dr}, *} \ln 10} \\
& \times\left[r_{\mathrm{dr}}^{2}-\left(\log s_{\mathrm{B}}^{\mathrm{dr}, *}-\log s_{\mathrm{A}}^{*}\right)^{2}\right]^{-1 / 2}
\end{aligned}
$$

Equations (5) and (6) form a system where the combined suction at point $\mathrm{B}^{\mathrm{dr}}, s_{\mathrm{B}}^{\mathrm{dr},}$, and the radius $r_{\mathrm{dr}}$ are the two unknown variables. However, solution of the system is not straightforward, and requires a numerical approach. In the present approach, Newton's method was adopted to solve the system of equations.

On wetting from the same initial point $\mathrm{A}\left(s_{\mathrm{A}}^{*}, S_{\mathrm{r}, \mathrm{A}}\right)$, the soil follows the wetting scanning path $\mathrm{AB}^{\text {wet }}$ shown in Fig. 3, rejoining the primary wetting path at point $\mathrm{B}^{\text {wet }}$ 
$\left(s_{\mathrm{B}}^{\text {wet, }}{ }^{*}, S_{\mathrm{r}, \mathrm{B}}^{\text {wet }}\right)$. Similar to the drying scanning path, the wetting scanning path is assumed to be the arc of a circle in the $\log s^{*}-S_{\mathrm{r}}$ plane, centred on the vertical line passing through point $\mathrm{A}$. The circle and the primary wetting curve have a common tangent at point $\mathrm{B}^{\text {wet }}\left(s_{\mathrm{B}}^{\text {wet,* }}, S_{\mathrm{r}, \mathrm{B}}^{\mathrm{wet}}\right)$. The expressions for the scanning wetting path and its gradient at the current value of combined suction, $s^{*}$, are

$$
S_{\mathrm{r}, \mathrm{scan}}^{\mathrm{wet}}=S_{\mathrm{r}, \mathrm{A}}+r_{\mathrm{wet}}-\left[r_{\mathrm{wet}}^{2}-\left(\log s_{\mathrm{A}}^{*}-\log s^{*}\right)^{2}\right]^{1 / 2}
$$

and

$$
\frac{\partial S_{\mathrm{r}, \mathrm{scan}}^{\mathrm{wet}}}{\partial s^{*}}=-\frac{\log s_{\mathrm{A}}^{*}-\log s^{*}}{s^{*} \ln 10}\left[r_{\mathrm{wet}}^{2}-\left(\log s_{\mathrm{A}}^{*}-\log s^{*}\right)^{2}\right]^{-1 / 2}
$$

Similar to drying, the following system of equations needs to be solved, in terms of the radius, $r_{\mathrm{wet}}$, and the combined suction at point $\mathrm{B}^{\text {wet }}, s_{\mathrm{B}}^{\text {wet,** }}$

$$
\frac{1-\left(1 / s_{0}^{*}\right) s_{\mathrm{B}}^{\text {wet, }}{ }^{*}}{1+\alpha_{\mathrm{w}} s_{\mathrm{B}}^{\text {wet, }}{ }^{*}}=S_{\mathrm{r}, \mathrm{A}}+r_{\mathrm{wet}}-\left[r_{\mathrm{wet}}^{2}-\left(\log s_{\mathrm{A}}^{*}-\log s_{\mathrm{B}}^{\text {wet, }}{ }^{*}\right)^{2}\right]^{1 / 2}
$$

and

$$
\begin{aligned}
-\frac{\left(1 / s_{0}^{*}\right)+\alpha_{\mathrm{W}}}{\left(1+\alpha_{\mathrm{w}} s_{\mathrm{B}}^{\text {wet, }}{ }^{*}\right)^{2}}= & -\frac{\log s_{\mathrm{A}}^{*}-\log s_{\mathrm{B}}^{\mathrm{wet}, *}}{s_{\mathrm{B}}^{\text {wet, }} \ln 10} \\
& \times\left[r_{\mathrm{wet}}^{2}-\left(\log s_{\mathrm{A}}^{*}-\log \mathrm{s}_{\mathrm{B}}^{\text {wet, }}{ }^{*}\right)^{2}\right]^{-1 / 2}
\end{aligned}
$$

For the solution of the system the Newton method was once more employed.

Model parameters. Five model parameters are required to define the hysteretic SWRC model described above

(a) two fitting parameters $\alpha_{\mathrm{d}}$ and $\alpha_{\mathrm{w}}$, for the primary drying and wetting paths respectively

(b) the suctions $s_{\text {air }}$ and $s_{0}^{*}$, that is, at the air-entry point (assumed independent of the specific volume, $v$ ) and at zero degree of saturation

(c) the parameter $\psi$ controlling the effect of specific volume on the retention behaviour.

The model parameters dictate the shape and position of the primary curves, which remain unvarying during the analysis. By contrast, the scanning paths are not directly controlled by the model parameters; their shape is always circular in the $\log s^{*}-S_{\mathrm{r}}$ plane, and the actual path followed is determined primarily by the initial retention state (point A in Fig. 3) and indirectly by the model parameters through the necessity of joining the primary paths with a common tangent. This lack of explicit control over the scanning paths could be regarded as a limitation of the model, which, however, guarantees simplicity.

\section{Implementation}

The three-dimensional hysteretic SWRC model was implemented in ICFEP. The numerical procedure requires that, depending on the combined suction change for the current increment of the analysis and on the level of combined suction, the software needs to select the appropriate path. The combined suction change indicates the direction of hydraulic loading (i.e. drying or wetting), while, based on the combined suction level itself, distinction is made in the employment of the corresponding primary and scanning paths.

For this procedure to be feasible, a number of variables need to be stored during the analysis. It is essential to register information concerning the last retention point before a change in the direction of hydraulic loading is detected. This point is commonly referred to as the reversal point. If the soil is dried from an initial point $\mathrm{A}$, shown in Fig. 4, to point $\mathrm{B}$, point $\mathrm{A}$ is considered to be the reversal point for this drying path. If the soil is subsequently wetted to point $\mathrm{C}$, point $\mathrm{B}$ is the new reversal point for this wetting path, and point $\mathrm{C}$ is the reversal point for the subsequent drying path $\mathrm{CD}$.

The variables stored are herein referred to as reversal parameters, and consist of the following quantities, which require recalculation every time a reversal in the direction of hydraulic loading occurs

(a) the combined suction, $s_{\text {rev }}^{*}$, and

(b) the degree of saturation, $S_{\mathrm{r}, \mathrm{rev}}$, of the reversal retention point

(c) the radius of the corresponding circle, $r$

(d) the combined suction, $s_{\text {common }}^{*}$, at the intersection point with the primary wetting curve if a reversal from drying to wetting has been detected, and with the primary drying path if a change from wetting to drying has been detected

(e) the direction of hydraulic loading: 1.0 for drying and $-1 \cdot 0$ for wetting.

The initialisation and updating of the reversal parameters are of central importance, and are now considered.

Initialisation of reversal parameters. The initial soil state, consisting of the stress state as well as of the degree of saturation and the specific volume, has to be established at the beginning of the finite-element analysis. For initialisation of the reversal parameters drying is assumed, and the direction of hydraulic loading is set equal to $1 \cdot 0$. If $s \leqslant s_{\text {air }}$ (i.e. full saturation) or $s^{*} \geqslant s_{0}^{*}$ the model is not employed in the analysis, and the reversal parameters are set to the values presented for both cases in Table 1 .

For unsaturated conditions for which $s>s_{\text {air }}$ and $s^{*}<s_{0}^{*}$ the initial combined suction is used in the calculation of the corresponding degrees of saturation on the primary drying and wetting curves, $S_{\mathrm{r}}^{\mathrm{dr}}$ and $S_{\mathrm{r}}^{\text {wet }}$, respectively, which should bound the initial degree of saturation, $S_{\mathrm{r}}$. In case the latter is found to lie outside the limiting values $S_{\mathrm{r}}^{\mathrm{dr}}$ and $S_{\mathrm{r}}^{\mathrm{wet}}$, an error message is issued and the program is terminated. Furthermore, the program checks whether the initial retention point prescribed lies on one of the two primary curves, and adopts the exact degree of saturation computed applying the rele-

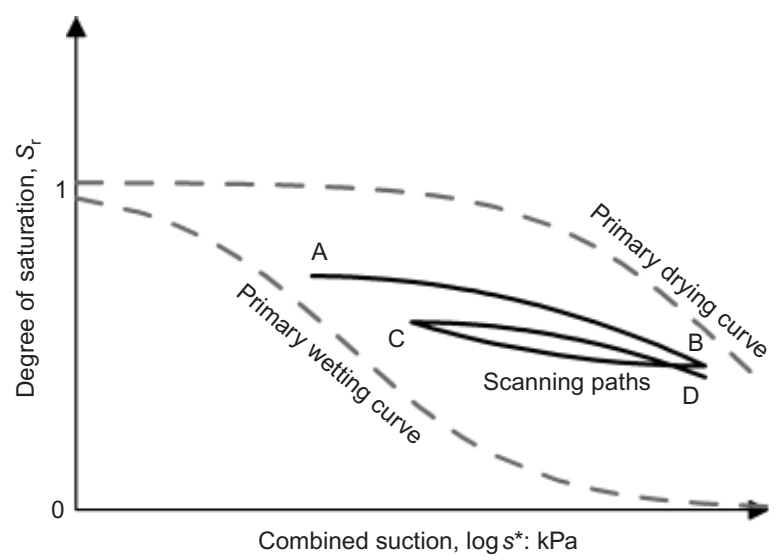

Fig. 4. Wetting and drying cycles from initial retention point $A$ 
Table 1. Initialisation of reversal parameters

\begin{tabular}{|c|c|c|c|c|c|}
\hline & Full saturation, $s \leqslant s_{\text {air }}$ & $s^{*} \geqslant s_{0}^{*}$ & On primary drying curve & On primary wetting curve & Within primary curves \\
\hline$s_{\mathrm{rev}}^{*}$ & $0 \cdot 0$ & $s_{0}^{*}$ & $s^{*}$ & $s^{*}$ & $s^{*}$ \\
\hline$S_{\mathrm{r}, \mathrm{rev}}$ & $1 \cdot 0$ & $0 \cdot 0$ & $S_{\mathrm{r}, \mathrm{pr}}^{\mathrm{dr}}$ & $S_{\mathrm{r}, \mathrm{pr}}^{\mathrm{wet}}$ & $S_{\mathrm{r}}$ \\
\hline$s_{\text {common }}^{*}$ & $0 \cdot 0$ & $s_{0}^{*}$ & $s^{*}$ & $s_{\mathrm{B}}^{\mathrm{dr}, *}$ & $s_{\mathrm{B}}^{\mathrm{dr}, *}$ \\
\hline$r$ & $0 \cdot 0$ & $0 \cdot 0$ & $0 \cdot 0$ & $r_{\mathrm{dr}}$ & $r_{\mathrm{dr}}$ \\
\hline Direction & $1 \cdot 0$ (drying) & $1 \cdot 0$ (drying) & $1 \cdot 0$ (drying) & $1 \cdot 0$ (drying) & $1 \cdot 0$ (drying) \\
\hline
\end{tabular}

vant model parameter, $\alpha_{\mathrm{d}}$ or $\alpha_{\mathrm{w}}$. The combined suction and the calculated degree of saturation form the coordinates of the initial reversal point, $s_{\text {rev }}^{*}$ and $S_{\mathrm{r}, \mathrm{rev}}$.

If the point is found to be positioned on the primary drying curve (tolerance of \pm 0.02 on the degree of saturation, $S_{\mathrm{r}}$ ), the combined suction $s_{\text {common }}^{*}$ is assumed to be equal to $s_{\text {rev }}^{*}=s^{*}$, and the radius, $r$, is set to 0.0 . If, on the other hand, the initial retention point is positioned on the primary wetting curve, the system of equations (5) and (6) needs to be solved in order to obtain the combined suction at the common point, $s_{\text {common }}^{*}=s_{\mathrm{B}}^{\mathrm{dr}, *}$, and the radius of the corresponding circle, $r=r_{\mathrm{dr}}$. The same system of equations also needs to be solved if the initial retention point lies within the primary paths for the reversal parameters $s_{\text {common }}^{*}$ and $r$ to be computed. In the latter case, $S_{\mathrm{r}, \text { rev }}$ is set equal to the initially prescribed degree of saturation, $S_{\mathrm{r}}$. The above procedure is summarised in Table 1.

Updating of reversal parameters. The direction of hydraulic loading is identified at the beginning of every analysis increment; a positive change of combined suction signifies drying, while wetting is detected in the opposite case. The occurrence of reversals in the direction of hydraulic loading is also checked at the beginning of every increment.

Detecting wetting while the direction of hydraulic loading is equal to 1.0 (drying) indicates that a reversal has occurred, and the direction is reset to -1.0 (wetting). The degree of saturation, $S_{\mathrm{r}}$, is evaluated, based on the thus far unchanged reversal parameters, for the combined suction at the end of the previous increment, and the two form the coordinates of the new reversal point, $s_{\text {rev }}^{*}$ and $S_{\text {r,rev }}$. Only then is the system of equations (9) and (10) solved, employing these coordinates, and the reversal parameters are updated to $s_{\text {common }}^{*}=s_{\mathrm{B}}{ }^{\text {wet, }}{ }^{*}$ and $r=r_{\text {wet }}$ (Table 2).

The process of solving the above-mentioned system of equations is avoided when $s \leqslant s_{\text {air }}$ or $s^{*} \geqslant s_{0}^{*}$, and the reversal parameters are set to the values presented in Table 2. Furthermore, if the newly evaluated reversal point lies close to the primary wetting path (tolerance of \pm 0.02 on the degree of saturation), the latter is followed on subsequent wetting, and the corresponding reversal parameters are also presented in Table 2.
A similar process is followed if drying is detected to occur while the direction of hydraulic loading is -1.0 (wetting). The direction is reset to 1.0 and the degree of saturation for the previous combined suction level is evaluated. The coordinates of the new reversal point are then updated and the system of equations (5) and (6) is solved, in order to calculate $s_{\text {common }}^{*}=s_{\mathrm{B}}^{\mathrm{dr},}$, and $r=r_{\mathrm{dr}}$ (Table 2). If $s \leqslant s_{\text {air }}$ or $s^{*} \geqslant s_{0}^{*}$, the solution of the system is not needed, as the reversal parameters are set to the values presented in Table 2. Finally, if the reversal point is found to lie close to the primary drying path (tolerance of \pm 0.02 on the degree of saturation), the latter is adopted.

The updated reversal parameters are stored, and are employed in the calculation of the degree of saturation, $S_{\mathrm{r}}$, corresponding to all the subsequent suction levels, as long as the direction of hydraulic loading remains unchanged.

A potential problem arises if an infinitesimal cycle of combined suction, which may be produced by computational oscillations or rounding errors in a numerical analysis, causes the reversal parameters to be updated, and consequently a new circle is obtained, altering the slope of the scanning path in the $\log s^{*}-S_{\text {r }}$ plane. This unrealistic prediction is not easy to avoid, as it is not possible to know whether the change in the direction of hydraulic loading is justified until the next change of suction is applied, in the following increment of the numerical analysis. While in principle numerical procedures exist to deal with this problem, they are beyond the scope of this paper.

Solution of the system of equations. As discussed above, the system of equations (5) and (6) or (9) and (10) needs to be solved to obtain the reversal parameters $s_{\text {common }}^{*}$ and $r$. However, the solution of the system is not straightforward, and requires a numerical approach. Newton's method (Press et al., 2007) was chosen, and proved to be robust and efficient. A limited number of iterations was generally required for convergence to be achieved (generally fewer than ten iterations were sufficient). Details of the application of the approach are given by Tsiampousi (2011). It should, however, be pointed out that the above systems can have two possible solutions, as sketched in Fig. 5 for drying. Therefore

Table 2. Updating of reversal parameters

\begin{tabular}{|c|c|c|c|c|c|c|c|c|}
\hline & \multicolumn{4}{|c|}{ Reversal from drying to wetting } & \multicolumn{4}{|c|}{ Reversal from wetting to drying } \\
\hline & $\begin{array}{l}\text { Solving the } \\
\text { system }\end{array}$ & $\begin{array}{l}\text { Full saturation, } \\
\qquad s \leqslant s_{\text {air }}\end{array}$ & $s^{*} \geqslant s_{0}^{*}$ & $\begin{array}{l}\text { On primary } \\
\text { wetting }\end{array}$ & $\begin{array}{l}\text { Solving the } \\
\text { system }\end{array}$ & $\begin{array}{l}\text { Full saturation, } \\
\qquad s \leqslant s_{\text {air }}\end{array}$ & $s^{*} \geqslant s_{0}^{*}$ & $\begin{array}{c}\text { On primary } \\
\text { drying }\end{array}$ \\
\hline$s_{\mathrm{rev}}^{*}$ & $\mathrm{~s}^{*}$ former & $0 \cdot 0$ & $s_{0}^{*}$ & $\mathrm{~s}^{*}$ former & $s_{\mathrm{eq}}^{*}$ former & $0 \cdot 0$ & $s_{0}^{*}$ & $\mathrm{~s}^{*}$ former \\
\hline$S_{\mathrm{r}, \mathrm{rev}}$ & $S_{r}$ former & $1 \cdot 0$ & $0 \cdot 0$ & $S_{\mathrm{r}, \mathrm{pr}}^{\mathrm{wet}}$ & Sr former & $1 \cdot 0$ & $0 \cdot 0$ & $S_{\mathrm{r}, \mathrm{pr}}^{\mathrm{dr}}$ \\
\hline$s_{\text {common }}^{*}$ & $s_{\mathrm{B}}^{\mathrm{wet}^{*}}$ & $0 \cdot 0$ & $s_{0}^{*}$ & $\mathrm{~s}^{*}$ former & $s_{\mathrm{B}}^{\mathrm{dr}, *}$ & $0 \cdot 0$ & $s_{0}^{*}$ & $\mathrm{~s}^{*}$ former \\
\hline & $r_{\text {wet }}$ & $0 \cdot 0$ & $0 \cdot 0$ & $0 \cdot 0$ & $\mathrm{r}_{\mathrm{dr}}$ & $0 \cdot 0$ & $0 \cdot 0$ & $0 \cdot 0$ \\
\hline Direction & $-1 \cdot 0$ & $-1 \cdot 0$ & $-1 \cdot 0$ & $-1 \cdot 0$ & $1 \cdot 0$ & $1 \cdot 0$ & $1 \cdot 0$ & $1 \cdot 0$ \\
\hline
\end{tabular}




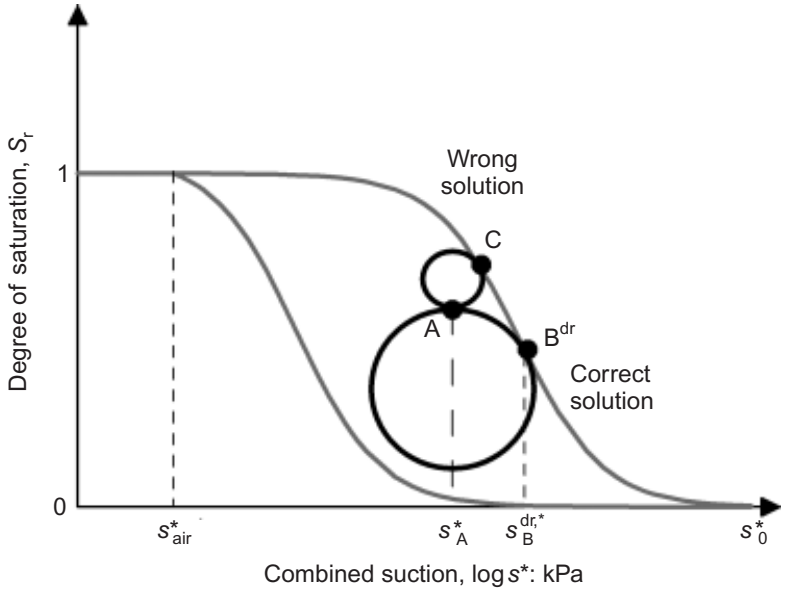

Fig. 5. Possible solutions of system of equations when drying from initial retention point $\mathrm{A}$

the validity of the calculated solutions needs to be checked to ensure the correct solution is adopted. For example, the small circle in Fig. 5 is obtained if the degree of saturation calculated is larger - or smaller for wetting - than the degree of saturation at the reversal point A: that is, the code has computed a negative radius, $r$, and as such this is the invalid solution.

Calculation of degree of saturation and of gradient of $S W R C$. Having stored the reversal parameters, the calculation of the degree of saturation, $S_{\mathrm{r}}$, as well as of the gradient of the SWRC, $R$, corresponding to the current value of suction, is straightforward. If the direction of hydraulic loading is $1 \cdot 0$, drying occurs, and distinction in the employment of the primary or the scanning drying path (equations (1) and (3) respectively) is based on comparison of the current combined suction, $s^{*}$, with the reversal parameter $s_{\text {common }}^{*}$. For combined suction levels higher than $s_{\text {common }}^{*}$ the primary drying path is employed; otherwise the scanning drying path is adopted.

If wetting is detected (the direction of hydraulic loading is $-1 \cdot 0)$, the scanning wetting path (equation (7)) is employed for combined suction levels higher than the reversal parameter $s_{\text {common }}^{*}$. By contrast, the primary wetting path (equation (1)) is adopted for lower combined suction levels.

\section{DEGREE OF SATURATION-DEPENDENT SOIL COMPRESSIBILITY WITH SUCTION}

In the three-dimensional hysteretic model presented above, knowledge of the specific volume and of its variation due to mechanical or hydraulic loading is necessary. Therefore the SWRC model needs to be combined with a constitutive model capable of reproducing the volumetric behaviour of unsaturated soils. The Georgiadis et al. (2005) elasto-plastic constitutive model was used here, in which the increase of apparent cohesion with suction is dependent on $S_{\mathrm{r}}$, providing a link between the constitutive model and the SWRC. The constitutive model is formulated in the equivalent suction, $s_{\text {eq }}$, equivalent mean stress, $p$ (defined as $p_{\text {net }}+s_{\text {air }}, p_{\text {net }}$ being the net mean stress), deviatoric stress, $J$, and Lode's angle $\theta$ space. The isotropic compression line in unsaturated conditions may be linear, bi-linear or non-linear (similar to Josa et al. (1992)). Similar to the BBM, it includes the concept of loading-collapse (LC) and suction-increase (SI) yield surfaces and a linear compression line in the $\log s-v$ plane (as shown in Fig. 6).

When successive increments of suction are applied under constant load $p$, the specific volume corresponding to each

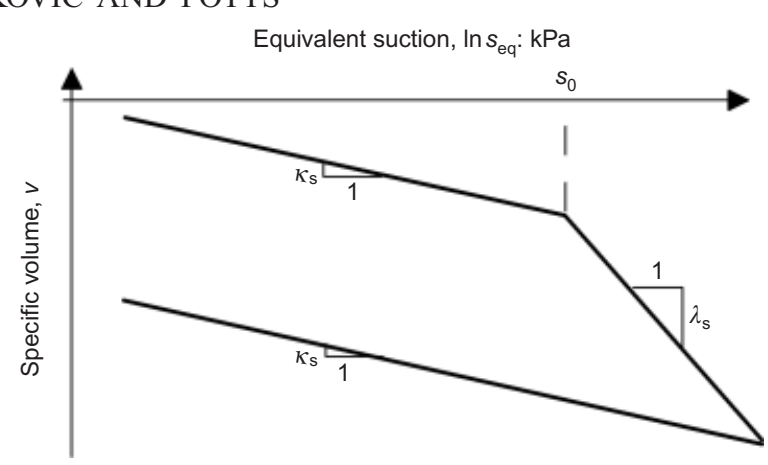

Fig. 6. Suction-induced compression line in Georgiadis et al. (2005) constitutive model; elastic and plastic coefficients of compressibility with suction, $\kappa_{\mathrm{s}}$ and $\lambda_{\mathrm{s}}$ respectively

one of them is calculated based on the value of $\kappa_{\mathrm{s}}$ and $\lambda_{\mathrm{s}}$ (see also Fig. 6). The specific volume may then be used in the SWRC model to calculate the successive increments of combined suction and, from those, $S_{\mathrm{r}}$.

Upon a cycle of suction (under constant applied load) that violates the SI surface, the $v-\log s$ line obtains the tri-linear shape shown in Fig. 6. Nonetheless, experimental data, such as those by Cunningham (2000), Melgarejo (2004), Jotisankasa (2005) (presented later in Fig. 9) and Monroy (2006), suggest that the $v-\log s$ relationship may not be linear, and its slope reduces with suction, rather than increasing as violation of the SI surface indicates. The specific volume (or equally the void ratio in the above references) tends to a limit value at large suction levels, where $S_{\mathrm{r}}$ tends to its residual value (in the SWRC model $S_{\mathrm{r}}$ is assumed to become 0.0 at combined suction $s_{0}^{*}$ ).

Considering the drying and wetting paths illustrated in Fig. 7, which are defined in $s-S_{\mathrm{r}}-v$ space, it would seem appropriate to assume that the compressibility with suction is a function of the degree of saturation. Indeed, projecting the hysteretic SWRC of the above figure in the three planes $\log s-S_{\mathrm{r}}, \log s-v$ and $v-S_{\mathrm{r}}$, as shown in Fig. 7 and in Figs 8(a), 8(b) and 8(c) respectively, it is seen that, in addition to the $\log s-S_{\mathrm{r}}$ relationship, the $\log s-v$ and $v-S_{\mathrm{r}}$ relationships are also non-linear and hysteretic.

The following expression is proposed as indicative of this behaviour

$$
\kappa_{\mathrm{s}}=\chi\left(S_{\mathrm{r}}\right)^{\omega}
$$

where $\chi$ and $\omega$ are fitting parameters $(\omega \geqslant 0 \cdot 0)$. For $\omega=0 \cdot 0$ a constant $\kappa_{\mathrm{s}}$ equal to $\chi$ is obtained.

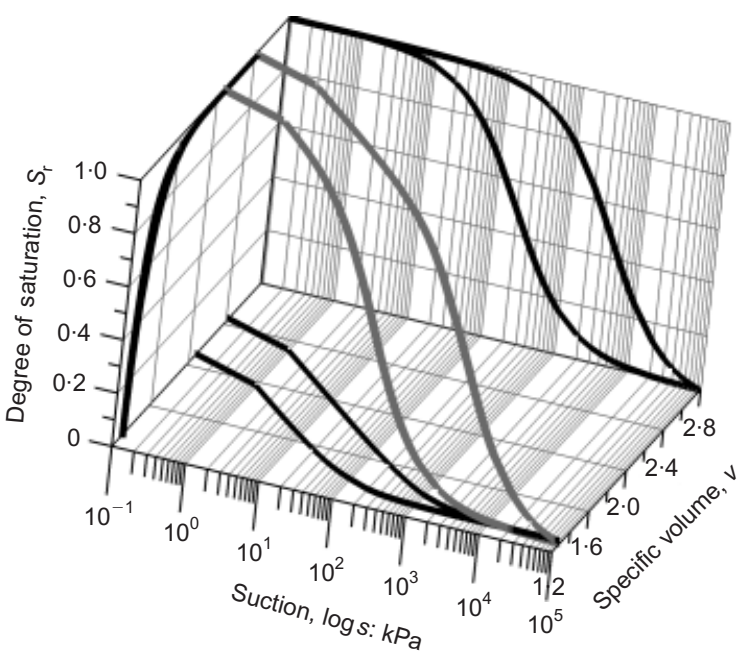

Fig. 7. Hysteretic SWRC in three-dimensional stress space $s-S_{\mathrm{r}}-v$ 


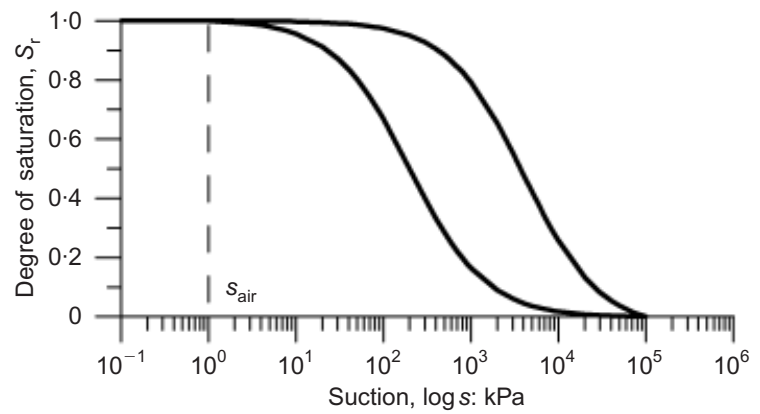

(a)

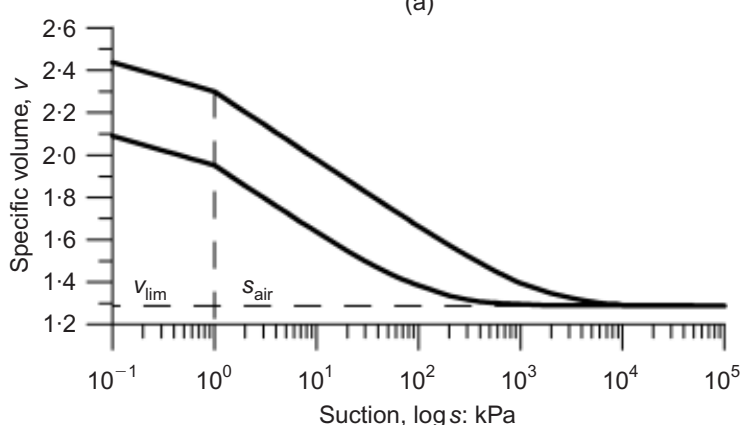

(b)

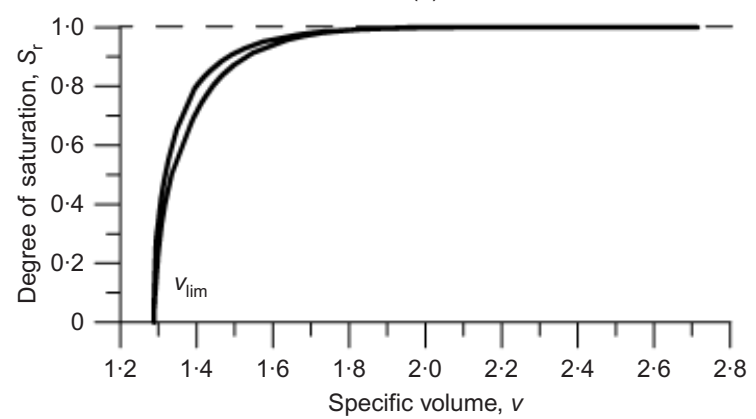

(c)

Fig. 8. Projection of hysteretic SWRC in (a) $\log s-S_{\mathrm{r}}$ (b) $\log s-v$ and (c) $v-S_{\text {r }}$ planes

$S_{\mathrm{r}}$ is calculated from the three-dimensional hysteretic SWRC model. However, there is a two-way coupling between equation (11) and the retention curve. Upon an increment of suction, equation (11) is initially employed, and $v$ is calculated based on the yet unchanged value of $S_{\mathrm{r}} . v$ is then used in the SWRC model to calculate $S_{\mathrm{r}}$, which is then used in equation (11) to obtain $v$, and so on. The iterative process is terminated when no changes in the value of $S_{\mathrm{r}}$ between successive iterations are obtained. Despite being more computationally expensive, the combination of the three-dimensional hysteretic SWRC model with the $S_{\mathrm{r}}$-dependent compressibility, $\kappa_{\mathrm{s}}$, concludes the threedimensional essence of the retention relationship; the degree of saturation, the suction and the specific volume are coupled, and as such they should be treated inseparably.

A non-hysteretic SWRC model may be employed in conjunction with equation (11). In this case, the $\log s-v$ relationship will also be non-hysteretic, but it will remain non-linear.

For fully saturated states $\left(s \leqslant s_{\text {air }}\right.$ and $\left.S_{\mathrm{r}}=1 \cdot 0\right)$, where according to the constitutive model the soil behaviour is described by the effective stress principle, equation (11) no longer applies, and the changes in volume are calculated based on the original formulation of the Georgiadis et al. (2005) model.

A consequence of the proposed approach is that irreversible volumetric strains are calculated upon cyclic changes of suction under constant loading, as subsequently demon- strated. The SI yield surface is rendered redundant. A similar type of irreversible strain was named paraelastic by Hueckel \& Nova (1979) (this approach is equivalent to modelling the SI surface to always follow the stress point, both on drying and on wetting, without coupled hardening of the LC yield surface - the coefficient $\lambda_{\mathrm{s}}$ rather than $\kappa_{\mathrm{s}}$ is then described by equation (11), and $\kappa_{\mathrm{s}}$ becomes redundant).

\section{CALIBRATION}

Calibration of the five SWRC model parameters and of the two parameters in equation (11) is not straightforward, and requires an iterative procedure of trial and error. Initially, it is assumed that $\kappa_{\mathrm{s}}=\chi$ (i.e. $\omega=0$ ), and the parameter $\chi$ is chosen so that the straight line produced in the $\log s-v$ plane lies close to the available experimental data. Subsequently, the parameters $\alpha_{\mathrm{d}}, \alpha_{\mathrm{w}}, s_{\text {air }}$ and $s_{0}^{*}$ are fitted to the experimental retention curve, assuming $\psi=0$ (i.e. no effect of $v$ ). If experimental data for the primary paths are available, the calibration of these parameters is straightforward. Knowledge solely of the scanning paths complicates the calibration process, though, as their position is not directly controlled by the model parameters, but is indirectly affected by the position of the primary paths. Therefore the values of the parameters need to be adjusted so that, starting from a known initial retention point, the predicted scanning path rejoins the congruent primary path in such a position that the experimental data are reproduced as closely as possible. Although this process may well result in different values being adopted for the model parameters by different users, the experimentally observed behaviour is successfully simulated, as subsequently demonstrated. Finally, calibration of the parameters $\psi$ and $\omega$ is achieved through trial and error. This process was used to simulate the experimental tests performed by Jotisankasa (2005) and Sharma (1998).

Jotisankasa (2005) tested samples of artificial soil A, which consists of $70 \%$ HPF 4 silt, 20\% Speswhite kaolin and $10 \%$ London Clay, subjected to static compaction to states dry-of-optimum. Starting from the as-compacted state, shown in Fig. 9 (point A), with initial specific volume, $v$, of $1 \cdot 7$, and degree of saturation, $S_{\mathrm{r}}, 0 \cdot 38$, a sample was wetted slowly to $1 \mathrm{kPa}$ of suction and was subsequently re-dried to an air-dried state (Fig. 9(a)). Another sample was dried from the same initial state, and a third one was dried from the retention point $\mathrm{B}$ (wetted from the as-compacted state, not shown here), also shown in Fig. 9(a). The corresponding changes in the specific volume, $v$, measured in the laboratory are shown in Fig. 9(b).

Employing the parameters summarised in Table 3, the retention paths and the volumetric response were numerically reproduced, as illustrated in Figs 9(a) and 9(b) respectively (solid lines). The retention behaviour was accurately simulated, demonstrating the ability of the model to adequately reproduce the experimentally observed behaviour.

Similarly, the computed specific volume is shown to be in good agreement with the laboratory data, and the paths reproduced correctly the exhibited limited change of specific volume at suctions higher than $1000 \mathrm{kPa}$.

Furthermore, a wetting-drying cycle performed by Sharma (1998) was also simulated. A compacted bentonitekaolin sample, tested in a triaxial cell under isotropic mean net stress of $10 \mathrm{kPa}$, was subjected to a cyclic change of suction from $300 \mathrm{kPa}$ to $20 \mathrm{kPa}$ and back. Consistent with the hydraulic hysteresis shown in Fig. 10(a), swelling was observed during wetting (path $\mathrm{A}-\mathrm{B}$ ), followed by greater compression upon drying (path $\mathrm{B}-\mathrm{C}$ ), as illustrated in Fig. 10(b). Employing the parameters in Table 3, the above behaviour was closely reproduced, in terms both of the 


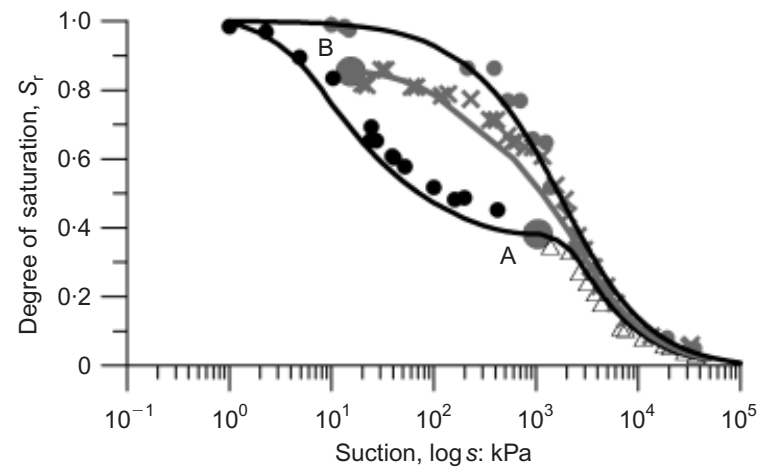

(a)

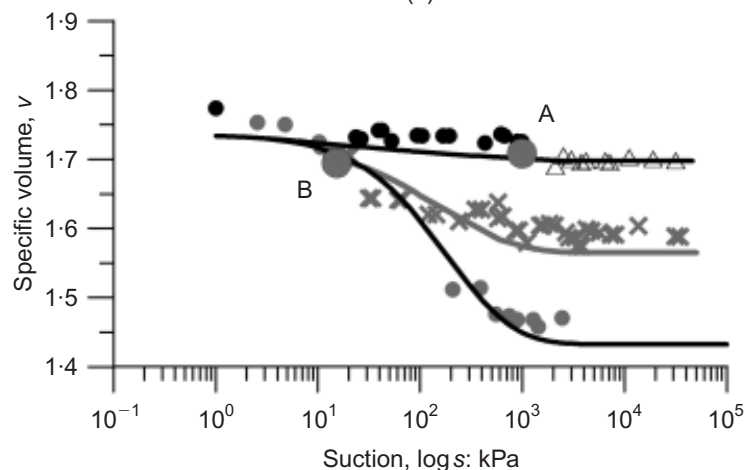

(b)

- Wetting from initial point A (lab.)

$\triangle \quad$ Drying from initial point $A$ (lab.)

- Drying from full saturation (lab.)

$\times \quad$ Drying from point $B(l a b$.

ICFEP

Fig. 9. Simulation of tests on compacted Soil A conducted by Jotisankasa (2005)

predicted degree of saturation and of the volumetric response to the cyclic changes of suction imposed.

\section{SUMMARY AND CONCLUSIONS}

A new three-dimensional hysteretic SWRC model was developed and implemented in the numerical code ICFEP. The model, which requires just five model parameters, accounts for the effect of specific volume on the retention behaviour exhibited by unsaturated soils, and therefore needs to be employed in combination with a constitutive model capable of reproducing the complex mechanical behaviour of unsaturated soils. However, modification of the constitutive model may be found necessary if, as in the case of the Georgiadis et al. (2005) model used herein, a unique relationship is assumed between the specific volume and the suction.

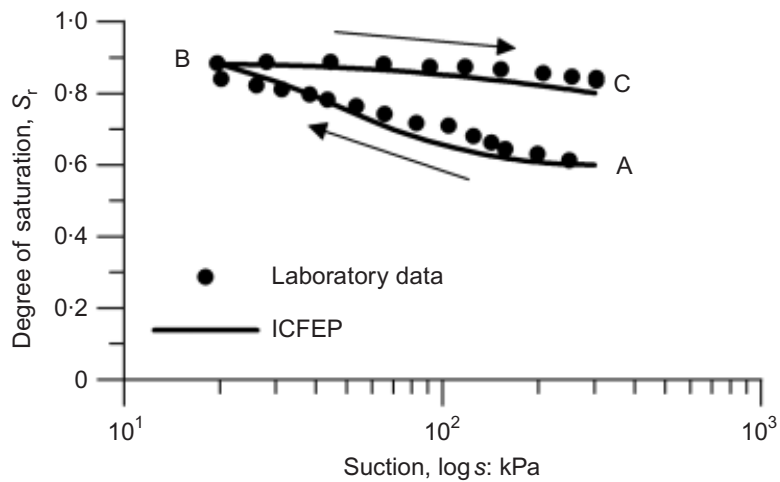

(a)

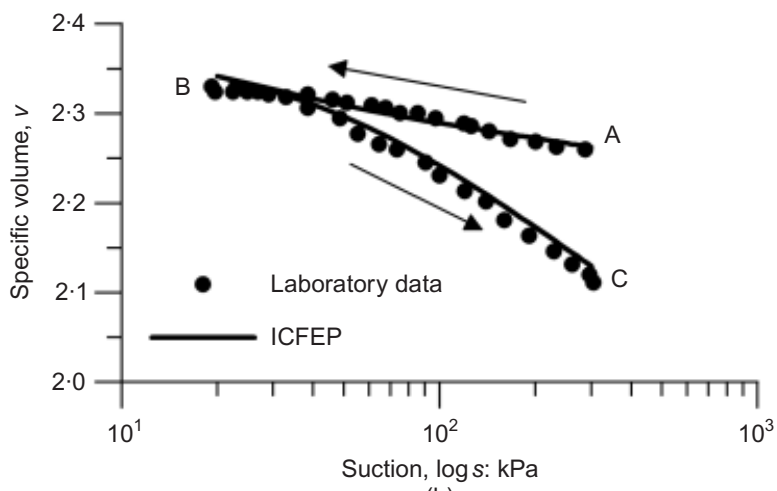

(b)

Fig. 10. Simulation of tests on compacted bentonite-kaolin mixture conducted by Sharma (1998)

A novel relationship, modelling the soil compressibility with suction as a function of the degree of saturation, was therefore proposed, introducing two additional parameters.

The three-dimensional hysteretic model, defined in $s-S_{\mathrm{r}}-v$ space, becomes a two-dimensional hysteretic curve when plotted in terms of combined suction, which is a function of the currently applied suction and of the specific volume resulting from the coupled effect of the mechanical and hydraulic loading. S-shaped curves are employed for the primary drying and wetting paths, which have two common points: the point of desaturation and at zero $S_{\mathrm{r}}$. The scanning paths are assumed to be arcs of circles, centred on the vertical line passing through the last reversal point, and to rejoin the corresponding primary path with a common tangent. Despite its simplified formulation, implementation of the hysteretic SWRC into a numerical code is relatively demanding, as the calculation of the scanning paths requires the solution of a system of non-linear equations, and a number of variables, termed reversal parameters, have to be stored during the analysis. The initialisation and update of those parameters are of central importance, and care should be taken for their correct and accurate implementation. The capability of the model to reproduce the scanning paths was shown to be satisfactory, despite the simple geometric shape assumed.

Table 3. Parameters for SWRC and $S_{\mathrm{r}}$-dependent $\kappa_{\mathrm{s}}^{*}$

\begin{tabular}{l|c|c|c|c|c}
\hline \multicolumn{2}{c|}{ SWRC } & \multicolumn{2}{c}{$S_{\mathrm{r}}$-dependent $\kappa_{\mathrm{s}}^{*}$} \\
\hline Parameters & Soil A & Compacted bentonite-kaolin & Parameters & Soil A & Compacted bentonite-kaolin \\
\hline$S_{\text {air }}$ & $1.0 \mathrm{kPa}$ & $0.0 \mathrm{kPa}$ & $\chi$ & 0.200 & 0.229 \\
$s_{0}^{*}$ & $1.0 \times 10^{5} \mathrm{kPa}$ & $1.0 \times 10^{5} \mathrm{kPa}$ & $\omega$ & 4.000 & - \\
$\alpha_{\mathrm{d}}$ & 0.0011 & $5.0 \times 10^{-5}$ & - & - & - \\
$\alpha_{\mathrm{W}}$ & 0.045 & $5.0 \times 10^{-3}$ & - & - & - \\
$\psi$ & 0.75 & 0.50 & - & - & - \\
\hline
\end{tabular}


Experimental evidence provided by Sharma (1998) and Jotisankasa (2005) indicates a hysteretic relationship between the specific volume and the applied suction, similar to the hysteresis of the retention curve. Employing the model developments presented, these laboratory results were successfully reproduced.

Future improvement of the proposed model can focus on accounting for the air-occlusion value of suction, which is generally smaller than the air-entry value of suction but was neglected here for simplicity. Furthermore, the concept of residual degree of saturation, obtained at large values of suction, may be also introduced $\left(S_{\mathrm{r}}\right.$ was equal to 0 for suction values higher than the input parameter $s_{0}^{*}$ ).

\section{NOTATION}

$J$ deviatoric stress

$p$ equivalent mean stress

$p_{\text {net }}$ net mean stress

$R$ gradient of soil-water retention curve

$r_{\mathrm{dr}}$ radius of circle on drying

$r_{\text {wet }}$ radius of circle on wetting

$S_{\mathrm{r}}$ degree of saturation

$S_{\mathrm{r}, \mathrm{pr}}^{\mathrm{dr}} \quad$ degree of saturation on primary drying curve

$S_{\mathrm{r}, \mathrm{pr}}^{\mathrm{wet}}$ degree of saturation on primary wetting curve

$s$ matric suction

$s^{*}$ combined suction

$s_{0}^{*} \quad$ combined suction at zero degree of saturation

$s_{\text {air }}$ air-entry value of suction

$s_{\mathrm{eq}}$ equivalent suction

$v$ specific volume

$v_{\lim }$ limit value of specific volume

$\alpha_{\mathrm{d}}, \alpha_{\mathrm{w}}$ fitting parameters for drying and wetting, respectively

$\theta$ Lode's angle

$\kappa_{\mathrm{S}}$ elastic coefficient of compressibility with suction

$\lambda_{\mathrm{s}}$ plastic coefficient of compressibility with suction

$\chi$ fitting parameter

$\omega$ fitting parameter

\section{REFERENCES}

Airo Farulla, C., Battiato, A. \& Ferrari, A. (2010). The void ratio dependency of the retention behaviour for a compacted clay. Proc. 5th Int. Conf. on Unsaturated Soils, Barcelona, 417-422.

Alonso, E. E., Gens, A. \& Josa, A. (1990). A constitutive model for partially saturated soils. Géotechnique 40, No. 3, 405-430, http://dx.doi.org/10.1680/geot.1990.40.3.405.

Cui, Y. J. \& Delage, P. (1996). Yielding and plastic behaviour of an unsaturated compacted silt. Géotechnique 46, No. 2, 291-311, http://dx.doi.org/10.1680/geot.1996.46.2.291.

Cunningham, M. R. (2000). The mechanical behaviour of compacted silty clay. $\mathrm{PhD}$ thesis, Imperial College, University of London, UK.

D’Onza, F., Gallipoli, D., Wheeler, S., Casini, F., Vaunat, J., Khalili, N., Laloui, L., Mancuso, C., Masin, D., Nuth, M., Pereira, J. M. \& Vassallo, R. (2011). Benchmark of constitutive models for unsaturated soils. Géotechnique 61, No. 4, 283-302, http://dx. doi.org/10.1680/geot.2011.61.4.283.

Gallipoli, D., Gens, A., Sharma, R. \& Vaunat, J. (2003a). An elasto-plastic model for unsaturated soil incorporating the effects of suction and degree of saturation on mechanical behaviour. Géotechnique 53, No. 1, 123-135, http://dx.doi.org/10.1680/ geot.2003.53.1.123

Gallipoli, D., Wheeler, S. J. \& Karstunen, M. (2003b). Modelling the variation of degree of saturation in a deformable unsaturated soil. Géotechnique 53, No. 1, 105-112, http://dx.doi.org/10. 1680/geot.2003.53.1.105

Gens, A. (2010). Soil-environment interactions in geotechnical engineering. Géotechnique 60, No. 1, 3-74, http://dx.doi.org/10. 1680/geot.9.P.109.

Georgiadis, K., Potts, D. M. \& Zdravkovic, L. (2005). Threedimensional constitutive model for partially and fully saturated soils. Int. J. Geomech. 5, No. 3, 244-255.

Hueckel, T. \& Nova, R. (1979). Paraelastic hysteresis of soils and rocks. Bull. Acad. Pol. Sci. Ser. Sci. Tech. 27, No. 1, 49-55.
Josa, A., Balmaceda, A., Gens, A. \& Alonso, E. E. (1992). An elastoplastic model for partially saturated soil exhibiting a maximum collapse. In Computational plasticity III (eds D. R. J. Owen, E. Onate and E. Hinton), pp. 815-826. Swansea, UK: Pineridge Press.

Jotisankasa, A. (2005). Collapse behaviour of compacted silty clay. $\mathrm{PhD}$ thesis, Imperial College, University of London, UK.

Li, X. S. (2005). Modelling of hysteresis response for arbitrary wetting/drying paths. Comput. Geotech. 32, No. 2, 133-137.

Lloret, M., Sanchez, M. \& Wheeler, S. J. (2009). Generalised elasto-plastic stress-strain and modified suction-degree of saturation relations of a fully coupled model. Proc. 4th Asia Pacific Conf. on Unsaturated Soils, Newcastle, 667-672.

Melgarejo, M. L. C. (2004). Laboratory and numerical investigations of soil-water retention curves. $\mathrm{PhD}$ thesis, Imperial College, University of London, UK.

Monroy, R. (2006). The influence of load and suction changes on the volumetric behaviour of compacted London clay. $\mathrm{PhD}$ thesis, Imperial College, University of London, UK.

Nuth, M. \& Laloui, L. (2008). Advances in modelling hysteretic water retention curve in deformable soils. Comput. Geotech. 35, No. 6, 835-844.

Pedroso, D. M. \& Williams, D. J. (2010). A novel approach for modelling soil water characteristic curves with hysteresis. Comput. Geotech. 37, No. 3, 374-380.

Potts, D. M. \& Zdravkovic, L. (1999). Finite element analysis in geotechnical engineering: Theory. London, UK: Thomas Telford.

Press, W. H., Teukolsky, S. A., Vetterling, W. T. \& Flannery, B. P. (2007). Numerical recipes: the art of scientific computing. Cambridge, UK: Cambridge University Press.

Romero, E., Gens, A. \& Lloret, A. (1999). Water permeability, water retention and microstructure of unsaturated compacted Boom clay. Engng Geol. 54, No. 1-2, 117-127.

Salager, S., El Youssoufi, M. S. \& Saix, C. (2010). Definition and experimental determination of a soil-water retention surface. Can. Geotech. J. 47, No. 6, 609-622.

Sharma, R. S. (1998). Mechanical behaviour of unsaturated highly expansive clays. $\mathrm{PhD}$ thesis, University of Oxford, Oxford, UK.

Sheng, D., Fredlund, D. G. \& Gens, A. (2008). A new modelling approach for unsaturated soils using independent stress variables. Can. Geotech. J. 45, No. 4, 511-534.

Smith, P. G. C. (2003). Numerical analysis of infiltration into partially saturated soil slopes. $\mathrm{PhD}$ thesis, Imperial College, University of London, UK.

Sugii, T., Yamada, K. \& Kondou, T. (2002). Relationship between soil-water characteristic curve and void ratio. Proc. 3rd Int. Conf. on Unsaturated Soils, Recife, 209-214.

Sun, D., Sheng, D. \& Sloan, S. W. (2007). Elasto-plastic modelling of hydraulic and stress-strain behaviour of unsaturated soils. Mech. Mater. 39, No. 3, 212-221.

Tarantino, A. (2009). A water retention model for deformable soils. Géotechnique 59, No. 9, 751-762, http://dx.doi.org/10.1680/ geot.7.00118.

Toll, D. G. (1990). A framework for unsaturated soil behavior. Géotechnique 40, No. 1, 31-44, http://dx.doi.org/10.1680/geot. 1990.40.1.31

Tsiampousi, A. (2011). Numerical analyses of slopes in unsaturated soils. PhD thesis, Imperial College London, UK.

Tsiampousi, A., Zdravkovic, L. \& Potts, D. M. (2010). Modelling of the hysteretic soil-water retention curve for unsaturated soils. Proc. 7th Eur. Conf. Numer. Methods Geotech. Engng, Trondheim, 331-336.

Van Genuchten, M. T. (1980). A closed-form equation for predicting the hydraulic conductivity of unsaturated soils. Soil Sci. Soc. Am. J. 44, No. 5, 892-898.

Vanapalli, S. K., Fredlund, D. G. \& Pufahl, D. E. (1999). The influence of soil structure and stress history on the soil-water characteristics of a compacted till. Géotechnique 49, No. 2, 143-159, http://dx.doi.org/10.1680/geot.1999.49.2.143.

Vaunat, J., Romero, E. \& Jommi, C. (2000). An elasto-plastic hydromechanical model for unsaturated soils. In Experimental evidence and theoretical approaches in unsaturated soils (eds A. Tarantino and C. Mancuso), pp. 121-138. Rotterdam, the Netherlands: Balkema.

Wheeler, S. J. (1996). Inclusion of specific water volume within an 
elasto-plastic model for unsaturated soil. Can. Geotech. J. 33 No. 1, 42-57.

Wheeler, S. J. \& Sivakumar, V. (1995). An elasto-plastic critical state framework for unsaturated soil. Géotechnique 45, No. 1, 35-53, http://dx.doi.org/10.1680/geot.1995.45.1.35.

Wheeler, S. J., Sharma, R. S. \& Buisson, M. S. R. (2003). Coupling of hydraulic hysteresis and stress-strain behaviour in unsaturated soils. Géotechnique 53, No. 1, 41-54, http://dx.doi.org/10.1680/ geot.2003.53.1.41.

Wong, T. T., Fredlund, D. G. \& Krahn, J. (1998). A numerical study of coupled consolidation in unsaturated soils. Can. Geotech. J. 35, No. 6, 926-937. 